\title{
Determination of Henry's law constants of organochlorine pesticides in deionized and saline water as a function of temperature
}

\author{
Banu Cetin ${ }^{\mathrm{a}}$, Serdar Ozer ${ }^{\mathrm{b}}$, Aysun Sofuoglu ${ }^{\mathrm{b}}$, Mustafa Odabasi ${ }^{\mathrm{a}, *}$ \\ ${ }^{a}$ Department of Environmental Engineering, Faculty of Engineering, Dokuz Eylul University, Kaynaklar Campus, Buca 35160, Izmir, Turkey \\ ${ }^{\mathrm{b}}$ Department of Chemical Engineering, Faculty of Engineering, Izmir Institute of Technology, Gulbahce-Urla 35460, Izmir, Turkey
}

Received 2 February 2006; accepted 5 April 2006

\begin{abstract}
The Henry's law constant $(H)$ is an important parameter that is required to estimate the air-water exchange of semivolatile organic compounds. Henry's law constants for 17 banned/restricted/currently used organochlorine pesticides (OCPs) were experimentally determined using a gas-stripping technique in deionized and saline water $(3 \%)$ over a temperature range of $5-35^{\circ} \mathrm{C} . H$ values (at $25^{\circ} \mathrm{C}$ ) ranged between $0.066 \pm 0.037 \mathrm{~Pa} \mathrm{~m}^{3} \mathrm{~mol}^{-1}$ (endosulfan II) and $62.0 \pm 24.2 \mathrm{~Pa} \mathrm{~m}^{3} \mathrm{~mol}^{-1}$ (heptachlor) in deionized water while the range in saline water was $0.28 \pm 0.03 \mathrm{~Pa} \mathrm{~m}^{3} \mathrm{~mol}^{-1}$ $(\gamma-\mathrm{HCH})$ and $135.2 \pm 31.3 \mathrm{~Pa} \mathrm{~m}^{3} \mathrm{~mol}^{-1}$ (heptachlor). The increase in dimensionless Henry's law constants $\left(H^{\prime}\right)$ for OCPs over the studied temperature range was between $3(\gamma-\mathrm{HCH})-19$ times (chlorpyrifos) and 3 (endosulfan II)-80 times (transnonachlor) in deionized and saline water, respectively. The calculated enthalpies of phase change $\left(\Delta H_{\mathrm{H}}\right)$ were within the ranges previously reported for OCPs and other organic compounds $\left(23.8-100.2 \mathrm{~kJ} \mathrm{~mol}^{-1}\right)$. The salting-out constant, $k_{\mathrm{s}}$, ranged between $0.04(\gamma-\mathrm{HCH})$ and $1.80 \mathrm{~L} \mathrm{~mol}^{-1}$ (endosulfan II) indicating the importance of assessing the $H$ values of OCPs in saline water to accurately determine their partitioning and fate in seawater.
\end{abstract}

(C) 2006 Elsevier Ltd. All rights reserved.

Keywords: Organochlorine pesticides; Henry's law constant; Gas-stripping technique; Salting-out effect

\section{Introduction}

Organochlorine pesticides (OCPs) are a subgroup of semi-volatile organic compounds (SOCs) that were extensively used in agriculture from the 1950 s to the 1970s. Although most of them are currently banned, some of them are still in use (e.g. lindane, chlorpyrifos,

\footnotetext{
*Corresponding author. Tel.: 902324127122 ; fax: 902324530922 .

E-mail address: mustafa.odabasi@deu.edu.tr (M. Odabasi).
}

and endosulfan). These bio-accumulating pollutants are very persistent in the environment, and their chlorine content tends to enhance their persistency (Macdonald et al., 2000). Therefore, they can remain unchanged for a long time in the environment and as a result, they are capable of long-range transport. Previous measurements detected OCPs in a wide range of environmental compartments. They were detected in the snow, icecaps of Arctic and Antarctic environment, far from the original sites of their applications (Macdonald et al., 2000; Vallack et al., 1998). 
Several approaches based on multimedia fate and transport models have been proposed to determine the long-range transport potential of SOCs (Wania and Dugani, 2003; Palm et al., 2002). Recently, there has been a great interest in environmental fate of SOCs. However, accurate physical-chemical property data is required in order to use multimedia fate and transport models (Wania and Dugani, 2003; Palm et al., 2002). Several studies have reported physical-chemical properties of OCPs in the literature. However, the studies on Henry's law constants $(H)$ of OCPs are very scarce (Jantunen and Bidleman 2006; Sahsuvar et al., 2003; Jantunen and Bidleman, 2000; Rice et al., 1997; Kucklick et al., 1991), and most of them are estimated or determined only at a single temperature (Altschuh et al., 1999). Organic compounds are generally less soluble in saline water (seawater) than in pure water, therefore, the presence of dissolved inorganic salts has a significant effect on $H$ values (Schwarzenbach et al., 2003; Staudinger and Roberts, 2001; Xie et al., 1997; Rice et al., 1997; Kucklick et al., 1991; Gossett, 1987). However, previous studies investigating the effect of salinity on $H$ values of OCPs are also very scarce.

The Henry's law constant $(H)$ is an important parameter that plays a fundamental role in predicting the transport, behavior and fate of SOCs in the environment and it is required to model gas exchange in aquatic systems. The objective of this study was to measure the Henry's law constants of 17 OCPs as a function of temperature and to investigate the salting-out effect on measured values. Henry's law constants were measured at five different environmental temperatures in deionized water and at four temperatures in saline water by a commonly used gas-stripping technique. The enthalpies and entropies of phase change and saltingout constants were also determined.

\section{Experimental}

\subsection{Gas-stripping experiments}

The gas-stripping apparatus consisted of a $75 \mathrm{~cm}$ $\times 5 \mathrm{~cm}$ diameter water-jacketed glass reactor filled with $1 \mathrm{~L}$ deionized water at a depth of $50 \mathrm{~cm}$ (Odabasi et al., 2006; Cetin and Odabasi, 2005). The water depth was selected based on previous studies indicating that the equilibrium between gas and water phases is achieved at less than $50 \mathrm{~cm}$ of water depth (Sahsuvar et al., 2003; Harrison et al.,
2002; Jantunen and Bidleman, 2000; Bamford et al., 2000, 1999). The initial aqueous concentrations were set to $15 \%$ of the solubility of $p, p^{\prime}$-DDT that has the lowest water solubility among the 17 compounds. OCPs were prepared in $1 \mathrm{~mL}$ methanol and spiked into the water in the reactor to obtain concentrations $\left(800 \mathrm{ng} \mathrm{L}^{-1}\right)$ less than $15 \%$ of the solubility of $p, p^{\prime}-$ DDT $\left(0.0055 \mathrm{mg} \mathrm{L}^{-1}\right)$ (Altschuh et al., 1999). Initial aqueous concentrations were between $0.01 \%(\gamma-\mathrm{HCH})$ and $15 \%\left(p, p^{\prime}\right.$-DDT $)$ of the solubilities of OCPs. The volume of methanol added to the reactor was $0.1 \%$ of the total water volume in the reactor. The effect of methanol on the solubility of pesticides at this level is assumed to be negligible based on a previous study, demonstrating that spiking a solvent solution into the reactor versus coating the inside of the reactor with the solution and allowing the solvent to evaporate before adding water yields similar $H$ values for a diverse set of chemicals (chlorobenzenes, polychlorinated biphenyls, and polycyclic aromatic hydrocarbons) (ten Hulscher et al., 1992).

Then, $175 \mathrm{~mL} \mathrm{~min}^{-1}$ compressed chromatographic grade $\mathrm{N}_{2}$ was passed through a $40-\mu \mathrm{m}$-fritted glass diffuser from the bottom of the reactor. Prior to the reactor, the $\mathrm{N}_{2}$ purge gas was saturated with water vapor using a gas-washing bottle filled with deionized water. Flow rates of $\mathrm{N}_{2}$ were measured using a flow meter (rotameter) and the temperature was controlled by a constant-temperature circulated water bath. The rotameter calibration was checked occasionally (at three flow rates in duplicate, $n=6$ ) using a primary standard (soap-bubble meter). The average percent difference between two flow meters was $<3.0 \%(2.4 \pm 1.8 \%$, average $\pm \mathrm{SD})$.

A $5 \mathrm{~cm}$ section of the tube exiting the inner chamber was plugged with pre-baked silanized glass wool to prevent the escape of the water droplets that may be produced during the bubbling process. Vapor-phase OCPs were captured by an XAD-2 resin filled glass column. Water samples $(5 \mathrm{~mL})$ were drawn through a valve located at the base of the reactor at the start and end of each sampling period. Similarly, saline water experiments were conducted at four different temperatures $\left(5,15,25\right.$ and $\left.35^{\circ} \mathrm{C}\right)$ using a $3 \%$ solution prepared by dissolving pre-baked $\mathrm{NaCl}$ in deionized water. The amount of $\mathrm{NaCl}$ was selected to obtain a typical seawater salt concentration $\left(0.5 \mathrm{~mol} \mathrm{~L}^{-1}\right)$.

\subsection{Sample preparation and analysis}

Gas-phase samples were extracted into dichloromethane (DCM) in an ultrasonic bath for $30 \mathrm{~min}$. 
Water samples were liquid-liquid extracted three times with $5 \mathrm{~mL}$ DCM using a separatory funnel. Then, the solvent was exchanged into hexane and sample volumes were reduced to $1 \mathrm{~mL}$ under a gentle stream of pure nitrogen.

Prior to analysis, all samples were spiked with $10 \mathrm{pg}$ of internal standard (BDE-77, 3,3',4,4'-tetrabromodiphenyl ether). Samples were analyzed for OCPs with an Agilent $6890 \mathrm{~N}$ gas chromatograph (GC) equipped with a mass-selective detector (Agilent 5973 inert MSD) working at electron capture negative chemical ionization mode. A capillary column (HP-5 ms, $30 \mathrm{~m}, \quad 0.25 \mathrm{~mm}$, $0.25 \mu \mathrm{m})$ was used. The initial oven temperature was held at $50{ }^{\circ} \mathrm{C}$ for $1 \mathrm{~min}$ and raised to $100^{\circ} \mathrm{C}$ at $25^{\circ} \mathrm{C} \mathrm{min}{ }^{-1}, 100-300{ }^{\circ} \mathrm{C}$ at $5^{\circ} \mathrm{C} \mathrm{min}^{-1}$, and held for $7 \mathrm{~min}$. The injector and ion source, and quadrupole temperatures were 250,150 , and $150{ }^{\circ} \mathrm{C}$, respectively. High-purity methane was used as the reagent gas. The MSD was run in selected ion-monitoring mode. Compounds were identified based on their retention times, target and qualifier ions, and quantified using the internal standard calibration procedure.

\subsection{Quality control}

Blank XAD-2 resin and water samples were prepared to determine if there was any contamination during sample handling and preparation for analysis. The average amounts of blanks ranged between $0.03 \pm 0.03 \mathrm{ng}$ (endosulfan II) and $1.22 \pm 0.45 \mathrm{ng}$ (chlorpyrifos) for XAD-2 resin samples and between $0.02 \pm 0.01 \mathrm{ng}$ (cis-nonachlor) and $0.65 \pm 0.12 \mathrm{ng}$ (heptachlor epoxide) for aqueous samples. Generally, blank amounts were significantly lower than the sample amounts. Sample/ blank amount ratios ranged between 17.5 \pm 9.5 $(\gamma-\mathrm{HCH})-472.1 \pm 344.4$ (heptachlor) and $4.3 \pm 1.3$ ( $p, p^{\prime}$-DDE)-90.1 \pm 36.0 (cis-nonachlor) for gasphase and aqueous samples, respectively.

The limit of detection of the method (LOD, ng) was defined as the mean blank mass plus three standard deviations (LOD $=$ mean blank value $+3 \mathrm{SD}$ ). LODs ranged from $0.13 \mathrm{ng}$ (cis-nonachlor) to $2.57 \mathrm{ng}$ (chlorprifos) for gas-phase samples and from $0.05 \mathrm{ng}$ (cis-nonachlor) to $1.01 \mathrm{ng}$ (heptachlorepoxide) for aqueous samples. In general, samples were substantially higher than LODs. Sample amounts exceeding LODs were quantified and blank corrected using the average blank amounts.
Five-point calibration curves were used to calibrate the analytical system. In all cases, the $r^{2}$ was $>0.999$. A mid-point calibration standard was used to confirm the GC performance for every 12-h period.

Spike recoveries for water samples $(n=6)$ ranged between $64 \pm 9 \%$ (aldrin)-112 $\pm 11 \%(\gamma-\mathrm{HCH})$ and for gas-phase samples $(n=3)$ they were between $82 \pm 6 \%\left(p, p^{\prime}\right.$-DDD)- $115 \pm 4 \%\left(p, p^{\prime}\right.$-DDT). Concentrations of OCPs were corrected using their average recoveries.

A backup column was also placed in series with the adsorbent column in order to determine possible breakthrough of gas-phase chemicals during the experiments at 35 and $25^{\circ} \mathrm{C}$. The average amounts found on these backup columns were between $2.4 \pm 0.9 \%$ (chlorpyrifos) and $15.3 \pm 2.4 \%$ (endrin) at $35^{\circ} \mathrm{C}$ (average $\pm \mathrm{SD}, 5.6 \pm 2.3 \%$ ). At $25^{\circ} \mathrm{C}$, backup amounts were between $1.4 \pm 0.9 \%$ $(\alpha-\mathrm{HCH})$ and $10.6 \pm 3.4 \%\left(p, p^{\prime}\right.$-DDE) (except cisnonachlor, $18.2 \pm 1.0 \%$ ) (average $\pm \mathrm{SD}, 4.8 \pm 2.0 \%$ ) of the amounts found in first columns. These results indicated that the breakthrough of chemicals was not significant even at the highest gas-phase concentrations encountered at 35 and $25^{\circ} \mathrm{C}$.

\section{Data analysis}

The Henry's law constant is often expressed as (Bamford et al., 1999; Schwarzenbach et al., 1993):

$H=P_{\mathrm{g}} / C_{\mathrm{w}}$,

where $P_{\mathrm{g}}$ is the gas-phase partial pressure $(\mathrm{Pa})$ and $C_{\mathrm{w}}$ is the dissolved concentration $\left(\mathrm{mol} \mathrm{m}^{-3}\right)$.

Using the ideal gas law $[p=(n R T) / V]$ to convert partial pressure to moles per cubic meter $\left(\mathrm{mol} \mathrm{m}^{-3}\right)$ of air, dimensionless Henry's law constant $\left(H^{\prime}\right)$ can be obtained as

$H^{\prime}=H / R T$,

where $R$ is the ideal gas constant $\left(8.314 \mathrm{~Pa} \mathrm{~m}^{3}\right.$ $\mathrm{mol}^{-1} \mathrm{~K}^{-1}$ ) and $T$ is the absolute temperature $(\mathrm{K})$.

The temperature dependence of $H^{\prime}$ can be expressed as (Bamford et al., 1999)

$\ln H=-\Delta H_{\mathrm{H}} / R T+\Delta S_{\mathrm{H}} / R$,

where $\Delta H_{\mathrm{H}}\left(\mathrm{J} \mathrm{mol}^{-1}\right)$ and $\Delta S_{\mathrm{H}}\left(\mathrm{J} \mathrm{mol}^{-1} \mathrm{~K}^{-1}\right)$ are the enthalpy and entropy of the phase change from the dissolved phase to the gas phase, respectively.

After directly measuring $H^{\prime}$ at different temperatures, $\ln H^{\prime}$ versus $1 / T$ can be plotted and $\Delta H_{\mathrm{H}}$ and 
$\Delta S_{\mathrm{H}}$ can be obtained from the slope and the intercept, respectively.

Experimental $H^{\prime}$ values were calculated as follows:

$H^{\prime}=C_{\mathrm{g}} /\left[\left(C_{\mathrm{w}(n)}+C_{\mathrm{w}(n+1)}\right) / 2\right]$,

where $C_{\mathrm{g}}\left(\mathrm{ng} \mathrm{L}^{-1}\right)$ is the time-integrated gas-phase pesticides concentration and $C_{\mathrm{w}(n)}$ and $C_{\mathrm{w}(n+1)}$ are the dissolved pesticides concentrations $\left(\mathrm{ng} \mathrm{L}^{-1}\right)$ measured at the beginning and end of air sampling period, respectively.

\section{Results and discussion}

Two sets of $H^{\prime}$ experiments were conducted at five different environmental temperatures $(5,15,20,25$ and $35^{\circ} \mathrm{C}$ ) for deionized water and at four temperatures $\left(5,15,25\right.$, and $\left.35^{\circ} \mathrm{C}\right)$ for saline water. Durations of first and second set of experiments were $9 \mathrm{~h}(3 \times 3 \mathrm{~h})$ and $3 \mathrm{~h}(3 \times 1 \mathrm{~h})$, respectively. For each individual experiment, three $H^{\prime}$ values $(n=3)$ were calculated using the concentrations of OCPs determined in aqueous $(n=4)$ and gas-phase samples $(n=3)$ that were collected over the experimental duration. Up to six $H^{\prime}$ values for each OCP at each temperature were calculated as a result of two sets of experiments. However, since the aqueous pesticides concentrations were below the detection limit at the end of the sampling period, it was not possible to determine $H^{\prime}$ values for some experiments. The aqueous concentrations that were below detection limit may be due to the loss of OCPs by stripping or adsorption on the wall of glass vessel. The replicate determinations provide a measure of the precision of the experimental method. For most OCPs, the relative standard deviations associated with the mean $H^{\prime}$ value were less than $30 \%$ for both deionized and saline water and no systematic differences, within experimental variability, were observed among the different temperatures (Table 1). Also, the agreement between the two sets of experiments with different sampling periods

Table 1

Measured Henry's law constants $\left(\mathrm{Pa} \mathrm{m}^{3} \mathrm{~mol}^{-1}\right)$ at different temperatures between 5 and $35^{\circ} \mathrm{C}$ in deionized water and the literature values at $25^{\circ} \mathrm{C}$

\begin{tabular}{|c|c|c|c|c|c|c|}
\hline & $35^{\circ} \mathrm{C}$ & $25^{\circ} \mathrm{C}$ & $20^{\circ} \mathrm{C}$ & $15^{\circ} \mathrm{C}$ & $5^{\circ} \mathrm{C}$ & Literature, $25^{\circ} \mathrm{C}$ \\
\hline$\alpha-\mathrm{HCH}$ & $0.61 \pm 0.16$ & $0.30 \pm 0.021$ & $0.23 \pm 0.01$ & $0.16 \pm 0.03$ & $0.09 \pm 0.02$ & $0.74^{\mathrm{a}}, 1.2^{\mathrm{b}}, 0.39^{\mathrm{c}}$ \\
\hline$\gamma-\mathrm{HCH}$ & $0.39 \pm 0.08$ & $0.27 \pm 0.02$ & $0.19 \pm 0.01$ & $0.15 \pm 0.02$ & $0.13 \pm 0.02$ & $0.31^{\mathrm{a}}, 0.04^{\mathrm{b}}, 0.18^{\mathrm{c}}$ \\
\hline$p, p^{\prime}-\mathrm{DDT}$ & $2.8 \pm 0.39$ & $0.97 \pm 0.27$ & $0.69 \pm 0.15$ & $0.52^{-}$ & $0.19 \pm 0.04$ & $0.84^{\mathrm{b}}, 0.82^{\mathrm{c}}, 1.1^{\mathrm{d}}$ \\
\hline$p, p^{\prime}$-DDD & $2.1 \pm 0.40$ & $0.96 \pm 0.41$ & $0.74 \pm 0.26$ & $0.57 \pm 0.16$ & 0.33 & $0.67^{\mathrm{b}}, 0.21^{\mathrm{c}}, 0.50^{\mathrm{d}}$ \\
\hline$p, p^{\prime}-\mathrm{DDE}$ & $8.6^{-}$ & $5.1 \pm 2.7$ & $4.3^{-}$ & 3.0 & 1.3 & $4.2^{\mathrm{b}}, 1.7^{\mathrm{c}}, 4.2^{\mathrm{d}}$ \\
\hline ESLF I & $1.1 \pm 0.29$ & $0.8 \overline{2} \pm 0.21$ & $0.72 \pm 0.17$ & $0.47 \pm 0.09$ & $0.27 \pm 0.09$ & $0.72^{\mathrm{b}}, 0.70^{\mathrm{d}}$ \\
\hline ESLF II & $0.079 \pm 0.011$ & $0.066 \pm 0.037$ & $0.044 \pm 0.018$ & $0.037 \pm 0.012$ & 0.022 & $0.040^{\mathrm{b}}, 0.045^{\mathrm{d}}$ \\
\hline CHLPYR & $14.8 \pm 1.7$ & $3.6 \pm 1.2$ & $2.3 \pm 0.51$ & $2.1 \pm 0.17$ & $0.83 \pm 0.06$ & $2.4^{\mathrm{e}}, 0.38^{\mathrm{f}}$ \\
\hline ALD & $72.3 \pm 8.8$ & $50.0 \pm 34.5$ & $43.3 \pm 18.1$ & $37.6 \pm 26.8$ & $18.3 \pm 6.5$ & $4.5^{\mathrm{b}}, 65.2^{\mathrm{c}}, 23^{\mathrm{d}}$ \\
\hline DIELD & $2.2 \pm 0.18$ & $0.99 \pm 0.02$ & $0.84 \pm 0.37$ & $0.64 \pm 0.22$ & $0.28 \pm 0.04$ & $1.0^{\mathrm{b}}, 0.78^{\mathrm{c}}, 1.1^{\mathrm{d}}$ \\
\hline END & $0.88 \pm 0.23$ & $0.57 \pm 0.32$ & $0.46 \pm 0.14$ & $0.30 \pm 0.1$ & $0.18 \pm 0.02$ & $0.64^{\mathrm{b}}, 1.32^{\mathrm{c}}, 1.1^{\mathrm{d}}$ \\
\hline$\alpha-\mathrm{CHL}$ & $16.1 \pm 1.9$ & $5.5 \pm 1.1$ & $3.9 \pm 0.23$ & $3.5 \pm 1.6$ & $1.8 \pm 0.05$ & $4.3^{\mathrm{c}}, 5.7^{\mathrm{d}}, 27^{\mathrm{g}}$ \\
\hline$\gamma-\mathrm{CHL}$ & $44.8 \pm 13.7$ & $15.9 \pm 5.7$ & $10.6 \pm 1.7$ & $9.9 \pm 8.2$ & $3.3 \pm 0.6$ & $4.8^{\mathrm{c}}, 6.8^{\mathrm{d}}, 29.0^{\mathrm{g}}$ \\
\hline t-NONA & $34.0 \pm 8.7$ & $10.7 \pm 1.3$ & $7.1 \pm 0.80$ & $3.7^{-}$ & $2.2^{-}$ & $2.0^{\mathrm{c}}, 32.0^{\mathrm{g}}, 2.5^{\mathrm{h}}$ \\
\hline c-NONA & 1.5 & $0.60 \pm 0.15$ & $0.43 \pm 0.055$ & $0.36 \pm 0.09$ & $0.25 \pm 0.08$ & $0.86^{\mathrm{c}}$ \\
\hline HEPCHL & $82.6 \pm 21.2$ & $62.0 \pm 24.2$ & $40.1 \pm 9.8$ & $31.3 \pm 7.0$ & $19.2 \pm 1.9$ & $29.7^{\mathrm{b}}, 71.5^{\mathrm{c}}, 38^{\mathrm{d}}$ \\
\hline HEP EPOX & $3.3 \pm 0.78$ & $2.3 \pm 0.75$ & $1.5 \pm 0.46$ & $0.8 \overline{5} \pm 0.26$ & $0.60 \pm 0.15$ & $2.13^{\mathrm{b}}, 1.7^{\mathrm{d}}$ \\
\hline
\end{tabular}

$\alpha, \gamma$-Hexachlorocyclohexane isomers $(\alpha, \gamma-\mathrm{HCH}), p, p^{\prime}$-dichlorodiphenyltrichloroethane $\left(p, p^{\prime}\right.$-DDT), $p, p^{\prime}$-dichlorodiphenyldichloroethane ( $p, p^{\prime}$-DDD), $p, p^{\prime}$-dichlorodiphenyldichloroethylene ( $p, p^{\prime}$-DDE), endosulfan I (ESLF I), endosulfan II (ESLF II), chlorpyrifos (CHLPYR), aldrin (ALD), dieldrin (DIELD), endrin (END), $\alpha$-chlordane $(\alpha$-CHL), $\gamma$-chlordane $(\gamma$-CHL), trans-nonachlor (t-NONA), cis-nonachlor (c-NONA), heptachlor (HEPCHL), heptachlor epoxide (HEP EPOX).

${ }^{\mathrm{a}} \mathrm{Xiao}$ et al. (2004).

${ }^{\mathrm{b}}$ Altschuh et al. (1999).

${ }^{\mathrm{c}}$ Calculated as the ratio of $K_{\mathrm{OW}} / K_{\mathrm{OA}} . K_{\mathrm{OW}}$ from TOXNET (2005) and Chiou et al. (2005), $K_{\mathrm{OA}}$ from Shoeib and Harner (2002).

${ }^{\mathrm{d}}$ Shen and Wania (2005).

${ }^{\mathrm{e}}$ Calculated as the ratio of vapor pressure/solubility from TOXNET (2005).

${ }^{\mathrm{f}}$ Rice et al. (1997).

${ }^{\mathrm{g}}$ Jantunen and Bidleman (2006).

${ }^{\mathrm{h}}$ Meylan and Howard (1991). 
( 1 and $3 \mathrm{~h})$ was very $\operatorname{good}\left(r^{2}=0.90\right.$, slope $=1$, intercept $=0$ ).

The Henry's law is valid for dilute concentrations. For compounds that are slightly or even moderately soluble in water with a reasonable accuracy, $H$ can be approximated by the ratio of the compound's vapor pressure and its aqueous solubility (Schwarzenbach et al., 1993). In the present study, the initial pesticide concentrations in water were dilute (0.01-15\% of their solubility). Different sampling durations also enabled different aqueous concentrations and this resulted in $H^{\prime}$ measurements at different concentrations. No systematic changes in measured $H^{\prime}$ values were observed for different aqueous concentrations either in deionized or saline water. These results were consistent with the previous studies reviewed by Schwarzenbach et al. (1993), reporting that there were no significant effects of solute concentration on measured $H$ values.

The measured Henry's law constant values of OCPs in deionized water at five different temperatures are presented in Table 1, along with the literature values reported previously for $25^{\circ} \mathrm{C} . \mathrm{H}$ values without standard deviations in Table 1 are the averages of two measurements. Shen and Wania (2005) have compiled and evaluated the literature data and obtained final adjusted values of OCPs.
The agreement between the $H$ values measured at $25^{\circ} \mathrm{C}$ in this study and those reported by previous studies was very good especially for the final adjusted values reported by Shen and Wania (2005). $H$ values measured in the present study were also consistent with the values calculated as the ratio of octanol-water to octanol-air partition coefficients $\left(K_{\mathrm{OW}} / K_{\mathrm{OA}}\right)$ (Table 1$)$.

The measured $H$ values in saline water at four different temperatures are presented in Table 2. The studies on Henry's law constant in saline water are very scarce in the literature. Henry's law constants for only five OCPs in saline water are presented in Table 2 from the studies conducted by Kucklick et al. (1991) at $25^{\circ} \mathrm{C}$ and Rice et al. (1997) at $20^{\circ} \mathrm{C}$. In the present study, all of the $H$ values for saline water were higher than those measured in deionized water. Saline/deionized water ratios varied by a factor of 1.7 (p, $p^{\prime}$-DDD) to 8.5 (chlorpyrifos) at $25^{\circ} \mathrm{C}$, except $\gamma-\mathrm{HCH}\left(1.0\right.$ for $25^{\circ} \mathrm{C}$ and $1.0 \pm 0.1$, average $\pm \mathrm{SD}$ for $5,15,25$ and $35^{\circ} \mathrm{C}$ ) (Table 2). These results were attributed to the salting-out effect that reduces the water solubility and increases the $H$ values. Similarly, Kucklick et al. (1991) and Rice et al. (1997) have also observed the salting-out effect. But this effect was negligible for $\gamma$-HCH since the $H$ values measured for deionized water and saline water were nearly the same.

Table 2

Measured Henry's law constants $\left(\mathrm{Pa} \mathrm{m}^{3} \mathrm{~mol}^{-1}\right)$ at different temperatures between 5 and $35^{\circ} \mathrm{C}$ in saline water, saline to DI water ratios (at $\left.25^{\circ} \mathrm{C}\right)$, and average salting-out constants $\left(k_{\mathrm{s}}\right)$

\begin{tabular}{|c|c|c|c|c|c|c|c|}
\hline & $35^{\circ} \mathrm{C}$ & $25^{\circ} \mathrm{C}$ & $15^{\circ} \mathrm{C}$ & $5^{\circ} \mathrm{C}$ & $\begin{array}{l}\text { Saline/DI water, } \\
25^{\circ} \mathrm{C}\end{array}$ & $k_{\mathrm{s}}\left(\mathrm{L} \mathrm{mol}^{-1}\right)$ & Literature $H$ \\
\hline$\alpha-\mathrm{HCH}$ & $0.73 \pm 0.02$ & $0.53 \pm 0.07$ & $0.28 \pm 0.03$ & $0.15 \pm 0.04$ & 1.8 & $0.40 \pm 0.16$ & $0.94^{\mathrm{a}}$ \\
\hline$\gamma-\mathrm{HCH}$ & $0.43 \pm 0.05$ & $0.28 \pm 0.03$ & $0.15 \pm 0.01$ & $0.11 \pm 0.002$ & 1.0 & $0.04 \pm 0.04$ & $0.47^{\mathrm{a}}$ \\
\hline$p, p^{\prime}$-DDT & 5.5 & $3.4 \pm 0.64$ & $1.9 \pm 0.63$ & 1.17 & 3.5 & $1.08 \pm 0.41$ & \\
\hline$p, p^{\prime}$-DDD & 2.8 & $1.6 \pm 0.33$ & $0.78 \pm 0.39$ & $0.40 \pm 0.13$ & 1.7 & $0.27 \pm 0.12$ & \\
\hline$p, p^{\prime}-\mathrm{DDE}$ & 19.2 & $16.7 \pm 2.5$ & $5.9 \pm 1.0$ & $4.0 \pm 0.9$ & 3.3 & $0.68 \pm 0.39$ & \\
\hline ESLF I & $6.8 \pm 1.5$ & $4.77 \pm 1.03$ & $2.11 \pm 0.60$ & $1.08 \pm 0.32$ & 5.8 & $1.37 \pm 0.17$ & $12.9^{\mathrm{b}}$ \\
\hline ESLF II & $0.57 \pm 0.22$ & $0.47 \pm 0.17$ & $0.37 \pm 0.18$ & 0.20 & 7.4 & $1.80 \pm 0.14$ & $2.1^{\mathrm{b}}$ \\
\hline CHLPYR & 54.2 & $30.5 \pm 7.8$ & $8.4 \pm 4.6$ & 3.27 & 8.5 & $1.32 \pm 0.33$ & $0.49^{\mathrm{b}}$ \\
\hline ALD & 114.1 & $91.3 \pm 2.72$ & $57.3 \pm 13.0$ & 29.1 & 1.8 & $0.41 \pm 0.07$ & \\
\hline DIELD & $5.14 \pm 1.00$ & $4.0 \pm 1.12$ & $1.6 \pm 0.60$ & $0.67 \pm 0.12$ & 3.1 & $0.85 \pm 0.22$ & \\
\hline END & $2.0 \pm 0.39$ & $1.9 \pm 0.33$ & $0.96 \pm 0.35$ & $0.52 \pm 0.20$ & 3.3 & $0.91 \pm 0.15$ & \\
\hline$\alpha-\mathrm{CHL}$ & $79.7 \pm 14.5$ & $24.8 \pm 8.2$ & $7.2 \pm 2.5$ & $4.1^{-}$ & 4.5 & $0.99 \pm 0.38$ & \\
\hline$\gamma-\mathrm{CHL}$ & $351.9 \pm 70.2$ & $38.4 \pm 8.6$ & $13.7 \pm 6.4$ & 7.8 & 2.4 & $0.88 \pm 0.62$ & \\
\hline t-NONA & $241.2 \pm 40.8$ & $24.36 \pm 1.55$ & $9.0 \pm 4.0$ & 3.0 & 2.3 & $0.73 \pm 0.65$ & \\
\hline c-NONA & $8.2^{-}$ & $3.2 \pm 0.93$ & $1.5 \pm 0.75$ & 0.80 & 5.4 & $1.27 \pm 0.21$ & \\
\hline HEPCHL & 211.6 & $135.2 \pm 31.3$ & $83.5 \pm 29.1$ & $52.2 \pm 14.0$ & 2.2 & $0.79 \pm 0.09$ & \\
\hline HEP EPOX & $9.4 \pm 1.3$ & $7.8 \pm 2.0$ & $5.0 \pm 1.6$ & $2.1 \pm 0.56$ & 3.4 & $1.13 \pm 0.27$ & \\
\hline
\end{tabular}

${ }^{\text {a }}$ Kucklick et al. (1991) (at $25^{\circ} \mathrm{C}$ ).

${ }^{\mathrm{b}}$ Rice et al. (1997) (at $\left.20^{\circ} \mathrm{C}\right)$. 
There is a strong correlation between the experimental $H^{\prime}$ values of OCPs and temperature. Temperature dependence of four selected OCPs is shown in Fig. 1. For all OCPs, $H$ increases with temperature more than 3 times ( 3 times for $\gamma-\mathrm{HCH}$ and 18 times for chlorpyrifos) for deionized water over the studied temperature range. For saline water, $H$ increases with temperature by the factor of 2.9 (endosulfan II) and 80 (t-nonachlor). The variation in $H$ with temperature was expressed using the van't Hoff equation (Eq. (3)). Assuming enthalpy and entropy are independent of temperature over the experimental temperature range, the slope and intercept of the line were obtained from the plot of $(\ln H)$ vs. $(1 / T)$ yields the enthalpy $\left(\Delta H_{\mathrm{H}}\right.$, $\left.\mathrm{kJ} \mathrm{mol}^{-1}\right)$ and entropy $\left(\Delta S_{\mathrm{H}}, \mathrm{kJ} \mathrm{mol}^{-1} \cdot \mathrm{K}^{-1}\right)$ of phase change, respectively. The slopes $(B)$ and the intercepts $(A)$ for the Eq. (3) $[\ln H=A+B / T(K)]$ are presented in Table 3. The $r^{2}$ values for the plots of $(\ln H)$ vs. $(1 / T)$ ranged between 0.91-0.99 for deionized water and saline water (Table 3) indicating the assumption that $\Delta H_{\mathrm{H}}$ and $\Delta S_{\mathrm{H}}$ are constant over the experimental temperature range and that the temperature dependence of $H$ can be accurately modeled by van't Hoff equation is valid.

Table 4 shows calculated enthalpies and entropies of phase change determined in this study along with the literature values for the enthalpy of air-water exchange $\left(\Delta H_{\mathrm{H}}\right)$, enthalpy of vaporization $\left(\Delta H_{\mathrm{vap}}\right)$ and the enthalpy of phase transfer between octanol and air $\left(\Delta H_{\mathrm{OA}}\right) . \Delta H_{\mathrm{H}}$ values in this study ranged between $27.2-66.1 \mathrm{~kJ} \mathrm{~mol}^{-1}$ for deionized water and $23.8-100.2 \mathrm{~kJ} \mathrm{~mol}^{-1}$ for saline water. $\Delta H_{\mathrm{H}}$ values of 10 OCPs were reported in the literature. Paasivirta et al. (1999) have conducted a study on estimation of vapor pressures, solubilities, and Henry's law constants of persistent organic chemicals as a function of temperature. Temperature dependence of $H$ was estimated from the temperature dependence of both the vapor pressure and aqueous solubility. Their calculated $\Delta H_{\mathrm{H}}$ values and the results of other five studies were presented in
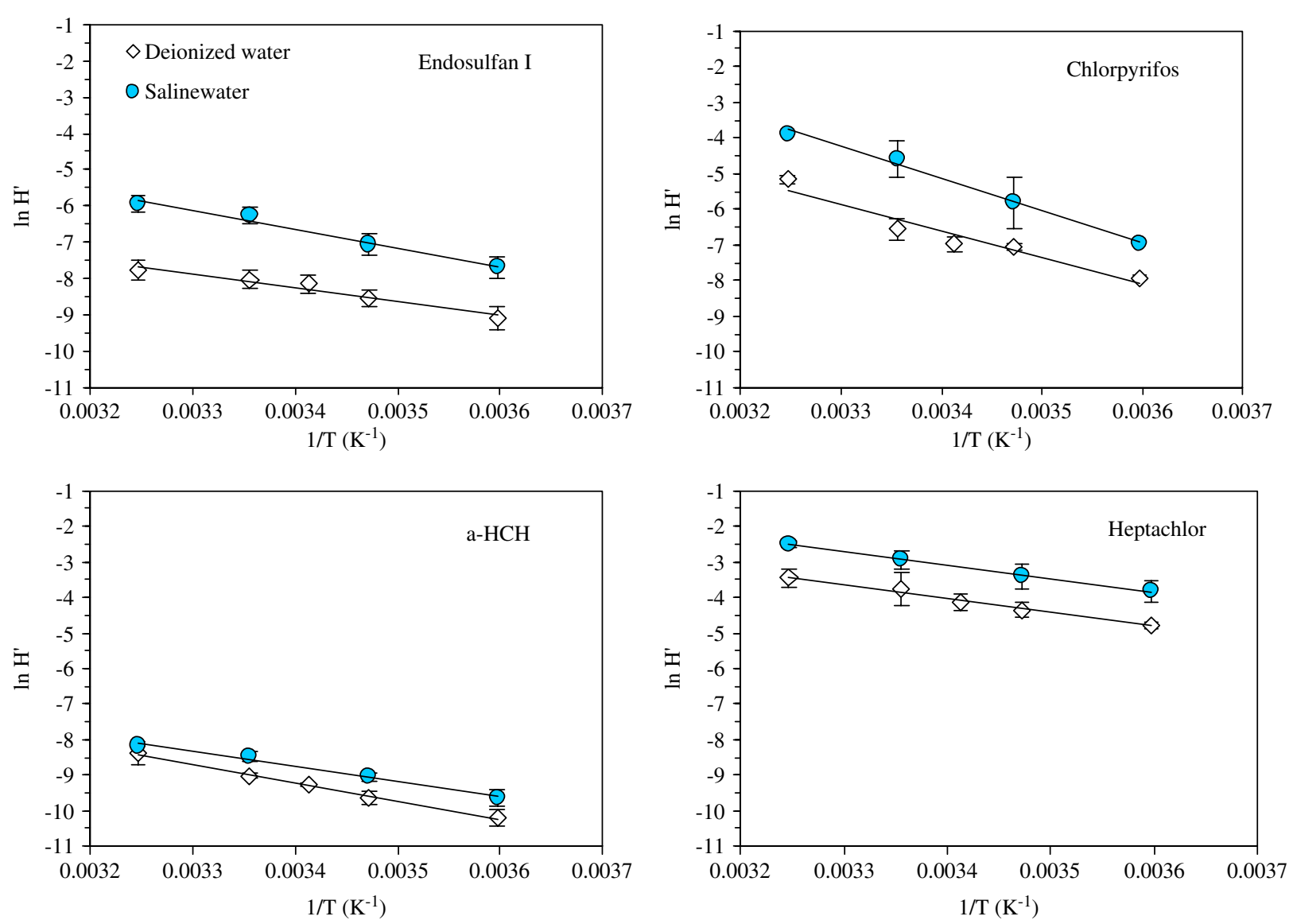

Fig. 1. Measured $H^{\prime}$ values for selected OCPs in deionized and saline water over the studied temperature range (5-35 $\left.{ }^{\circ} \mathrm{C}\right)$. Error bars are 1 SD. 
Table 3

The regression parameters ( \pm standard errors) for the equation $\ln H=A+B / T(K)$ for deionized and saline water

\begin{tabular}{|c|c|c|c|c|c|c|}
\hline & \multicolumn{3}{|c|}{ Deionized water } & \multicolumn{3}{|c|}{ Saline water } \\
\hline & $r^{2}$ & $A$ & $B$ & $r^{2}$ & $A$ & $B$ \\
\hline$\alpha-\mathrm{HCH}$ & 0.99 & $17.4 \pm 0.6$ & $-5516 \pm 168$ & 0.99 & $14.7 \pm 1.2$ & $-4596 \pm 345$ \\
\hline$\gamma-\mathrm{HCH}$ & 0.93 & $9.6 \pm 1.7$ & $-3266 \pm 506$ & 0.99 & $12.3 \pm 1.1$ & $-4043 \pm 335$ \\
\hline$p, p^{\prime}$-DDT & 0.99 & $25.1 \pm 1.8$ & $-7453 \pm 513$ & 0.99 & $16.2 \pm 0.7$ & $-4474 \pm 211$ \\
\hline$p, p^{\prime}$-DDD & 0.98 & $17.1 \pm 1.6$ & $-5071 \pm 463$ & 0.99 & $18.9 \pm 1.3$ & $-5538 \pm 372$ \\
\hline$p, p^{\prime}$-DDE & 0.96 & $27.8 \pm 3.0$ & $-7738 \pm 892$ & 0.93 & $19.4 \pm 3.3$ & $-5018 \pm 974$ \\
\hline ESLF I & 0.96 & $13.7 \pm 1.6$ & $-4157 \pm 461$ & 0.98 & $19.8 \pm 1.7$ & $-5470 \pm 499$ \\
\hline ESLF II & 0.99 & $9.6 \pm 0.9$ & $-3737 \pm 266$ & 0.98 & $8.7 \pm 1.0$ & $-2858 \pm 296$ \\
\hline CHLPYR & 0.97 & $27.7 \pm 4.0$ & $-7802 \pm 1164$ & 0.98 & $34.4 \pm 3.0$ & $-9327 \pm 887$ \\
\hline ALD & 0.98 & $16.8 \pm 1.1$ & $-3868 \pm 324$ & 0.95 & $18.9 \pm 2.4$ & $-4310 \pm 696$ \\
\hline DIELD & 0.99 & $19.4 \pm 1.2$ & $-5758 \pm 344$ & 0.97 & $21.4 \pm 2.6$ & $-6034 \pm 770$ \\
\hline END & 0.99 & $14.9 \pm 1.0$ & $-4620 \pm 303$ & 0.92 & $14.7 \pm 2.9$ & $-4257 \pm 861$ \\
\hline$\alpha-\mathrm{CHL}$ & 0.95 & $22.4 \pm 2.9$ & $-6108 \pm 844$ & 0.98 & $33.4 \pm 3.4$ & $-8998 \pm 995$ \\
\hline$\gamma-\mathrm{CHL}$ & 0.96 & $28.2 \pm 3.2$ & $-7584 \pm 927$ & 0.91 & $40.9 \pm 8.3$ & $-10950 \pm 2423$ \\
\hline t-NONA & 0.96 & $29.1 \pm 3.1$ & $-7953 \pm 908$ & 0.94 & $44.2 \pm 7.2$ & $-12054 \pm 2091$ \\
\hline c-NONA & 0.91 & $16.7 \pm 3.2$ & $-5076 \pm 923$ & 0.98 & $23.2 \pm 2.2$ & $-6554 \pm 658$ \\
\hline HEPCHL & 0.99 & $18.2 \pm 0.9$ & $-4252 \pm 268$ & 0.99 & $18.6 \pm 0.4$ & $-4085 \pm 115$ \\
\hline HEP EPOX & 0.95 & $18.2 \pm 2.3$ & $-5221 \pm 662$ & 0.94 & $16.4 \pm 2.7$ & $-4307 \pm 788$ \\
\hline
\end{tabular}

Table 4

Measured enthalpy $\left(\Delta H_{\mathrm{H}}\right)$ and entropy $\left(\Delta S_{\mathrm{H}}\right)$ of $H$ in this study for deionized and saline water, the previously reported enthalpies of air-water exchange $\left(\Delta H_{\mathrm{H}}\right)$, the enthalpies of vaporization $\left(\Delta H_{\mathrm{vap}}\right)$ and the enthalpies of phase transfer between octanol and air $\left(\Delta H_{\mathrm{OA}}\right)$

\begin{tabular}{|c|c|c|c|c|c|c|c|}
\hline & \multicolumn{2}{|c|}{ Deionized water } & \multicolumn{2}{|l|}{ Saline water } & \multicolumn{3}{|l|}{ Literature } \\
\hline & $\begin{array}{l}\Delta H_{\mathrm{H}} \\
\left(\mathrm{kJ} \mathrm{mol}^{-1}\right)\end{array}$ & $\begin{array}{l}\Delta S_{\mathrm{H}} \\
\left(\mathrm{kJ} \mathrm{mol}^{-1} \mathrm{~K}^{-1}\right)\end{array}$ & $\begin{array}{l}\Delta H_{\mathrm{H}} \\
\left(\mathrm{kJ} \mathrm{mol}^{-1}\right)\end{array}$ & $\begin{array}{l}\Delta S_{\mathrm{H}} \\
\left(\mathrm{kJ} \mathrm{mol}^{-1} \mathrm{~K}^{-1}\right)\end{array}$ & $\begin{array}{l}\Delta H_{\mathrm{H}} \\
\left(\mathrm{kJ} \mathrm{mol}^{-1}\right)\end{array}$ & $\begin{array}{l}\Delta H_{\mathrm{vap}}{ }^{\mathrm{d}} \\
\left(\mathrm{kJ} \mathrm{mol}^{-1}\right)\end{array}$ & $\begin{array}{l}\Delta H_{\mathrm{OA}}{ }^{\mathrm{e}} \\
\left(\mathrm{kJ} \mathrm{mol}^{-1}\right)\end{array}$ \\
\hline$\alpha-\mathrm{HCH}$ & 45.9 & 0.14 & 38.2 & 0.12 & $51.4^{\mathrm{a}}, 56.8^{\mathrm{b}}, 32.8^{\mathrm{c}}$ & 68.5 & 61.9 \\
\hline$\gamma-\mathrm{HCH}$ & 27.2 & 0.08 & 33.6 & 0.10 & $43.2^{\mathrm{a}}, 57.2^{\mathrm{b}}, 59.2^{\mathrm{c}}$ & 66.5 & 94.5 \\
\hline$p, p^{\prime}-\mathrm{DDT}$ & 62.0 & 0.21 & 37.2 & 0.13 & $64.5^{\mathrm{c}}$ & 93.2 & 88.1 \\
\hline$p, p^{\prime}-\mathrm{DDD}$ & 42.2 & 0.14 & 46.0 & 0.16 & $60.9^{\mathrm{c}}$ & 88.5 & 80.1 \\
\hline$p, p^{\prime}-\mathrm{DDE}$ & 64.3 & 0.23 & 41.7 & 0.16 & $63.0^{\mathrm{c}}, 39.1^{\mathrm{f}}$ & 87.2 & 98.0 \\
\hline ESLF I & 34.6 & 0.11 & 45.5 & 0.16 & $16.8^{\mathrm{a}}$ & 80.4 & 83.0 \\
\hline ESLF II & 31.1 & 0.08 & 23.8 & 0.07 & & 82.4 & \\
\hline CHLPYR & 64.9 & 0.23 & 77.5 & 0.29 & $22.8^{\mathrm{a}}$ & & \\
\hline ALD & 32.2 & 0.14 & 35.8 & 0.16 & & 75.1 & 71.0 \\
\hline DIELD & 47.9 & 0.16 & 50.2 & 0.18 & & 82.5 & 72.6 \\
\hline END & 38.4 & 0.12 & 35.4 & 0.12 & & & 84.9 \\
\hline$\alpha-\mathrm{CHL}$ & 50.8 & 0.19 & 74.8 & 0.28 & $60.5^{\mathrm{c}}, 34.2^{\mathrm{f}}$ & 82.0 & 97.5 \\
\hline$\gamma-\mathrm{CHL}$ & 63.1 & 0.23 & 91.0 & 0.34 & $59.3^{\mathrm{c}}, 29.2^{\mathrm{f}}$ & 80.7 & 96.4 \\
\hline t-NONA & 66.1 & 0.24 & 100.2 & 0.37 & $62.8^{\mathrm{c}}, 39.6^{\mathrm{f}}$ & 85.6 & 105 \\
\hline c-NONA & 42.2 & 0.14 & 54.5 & 0.19 & & 83.8 & 97.5 \\
\hline HEPCHL & 35.4 & 0.15 & 34.0 & 0.15 & & 76.4 & 66.2 \\
\hline HEP EPOX & 43.4 & 0.15 & 35.8 & 0.14 & & & \\
\hline
\end{tabular}

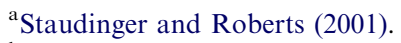

${ }^{\mathrm{b}}$ Xiao et al. (2004).

${ }^{\mathrm{c}}$ Paasivirta et al. (1999).

${ }^{\mathrm{d}}$ Hinckley et al. (1990).

${ }^{\mathrm{e}}$ Shoeib and Harner (2002).

${ }^{\mathrm{f}}$ Jantunen and Bidleman (2006). 
Table 4. Results of the present study were within these ranges. For deionized water, $\Delta H_{\mathrm{H}}$ values are lower than $\Delta H_{\text {vap }}$ values. This is consistent with thermodynamic principles that suggest the effect of temperature on $H\left(\Delta H_{\mathrm{H}}\right)$ should be lower than $\left(\Delta H_{\mathrm{vap}}\right)$ by an amount close or equal to enthalpy of solvation $\left(\Delta H_{\mathrm{SOL}}\right)$ (Schwarzenbach et al., 2003; Bamford et al., 2000). Therefore, $\Delta H_{\mathrm{SOL}}$ can be approximated by $\Delta H_{\mathrm{H}}=\Delta H_{\mathrm{VAP}}-\Delta H_{\mathrm{SOL}}$. For hydrophobic organic chemicals, $\Delta H_{\mathrm{SOL}}$ is often positive (Paasivirta et al., 1999). Paasivirta et al. (1999) have estimated the solubilities of OCPs as a function of temperature by equations based on mobile order theory. They have calculated that $\Delta H_{\mathrm{SOL}}$ values of eight OCPs including $\alpha-\mathrm{HCH}, \gamma-$ $\mathrm{HCH}, \alpha$-CHL, $\gamma$-CHL, trans-nonachlor, $p$ - $p^{\prime}$-DDT, $p$ - $p^{\prime}$-DDD, $p, p^{\prime}$-DDE, range between 21.4 and $31.0 \mathrm{~kJ} \mathrm{~mol}^{-1}$. In this study, $\Delta H_{\mathrm{SOL}}$ values of these eight compounds obtained using above equation were within these ranges (between 17.6 and $\left.31.2 \mathrm{~kJ} \mathrm{~mol}^{-1}\right)$ except $p, p^{\prime}$-DDD and $\gamma-\mathrm{HCH}(46.3$ and $39.3 \mathrm{~kJ} \mathrm{~mol}^{-1}$, respectively).

The presence of salts in aqueous solution affects the solubility of organic molecules through the salting-out effect (Demou and Donaldson, 2002). The salting-out coefficients of organic compounds are known to be related to their partial molar volumes (Kutsuna et al., 2005). In the present study, molar volumes of OCPs were used since their partial molar volumes were not available. Salting-out constants (ks) of OCPs increased with the increasing molar volume and the relationship was statistically significant $\left(r^{2}=0.36, p \& i t ; 0.01\right)$. However, molar volume could not account for all the variation in $\mathrm{ks}$ values. Recently, a similar relationship was also observed between the ks values of 2,2,2-trifluoroethyl formate, ethyl trifluoroacetate, and nonfluorinated analogous esters and their molar volumes (Kutsuna et al., 2005)

$\log \left(H^{*} / H\right)=k_{\mathrm{s}} C_{\mathrm{s}}$,

where $H^{*}$ is the Henry's law constant in saline water, $H$ is the Henry's law constant in deionized water, $k_{\mathrm{s}}$ is the Setschenow or the salting-out constant and $C_{\mathrm{s}}$ is the molar concentration of the salt solution. The measured $k_{\mathrm{s}}$ values ranged between $0.04(\gamma-\mathrm{HCH})$ and $1.80 \mathrm{~L} \mathrm{~mol}^{-1}$ (endosulfan II). Salting-out effect on the solubility of organic compounds was extensively examined in the literature for various organic compounds but not for OCPs. Calculated or experimentally determined $k_{\mathrm{s}}$ values of organic compounds range between 0.01 and $2.23 \mathrm{~L} \mathrm{~mol}^{-1}$ (Ni and Yalkowsky, 2003; Xie et al., 1997). Xie et al. (1997) have compiled the existing data on the salting-out effect of organic solutes, particularly for hydrocarbons and chlorinated hydrocarbons. There are significant differences in calculated and experimentally obtained $k_{\mathrm{s}}$ values. The calculated $k_{\mathrm{s}}$ value for naphthalene was $0.19 \mathrm{~L} \mathrm{~mol}^{-1}$ while experimentally determined ones were up to $0.62 \mathrm{~L} \mathrm{~mol}^{-1}$. Similar results were observed for hexacosane, estimated and experimental values were 0.521 and $2.230 \mathrm{~L} \mathrm{~mol}^{-1}$, respectively. Therefore, it is recommended to obtain $k_{\mathrm{s}}$ values experimentally since calculated values tend to be underestimated (Xie et al., 1997). These high $k_{\mathrm{s}}$ values experimentally obtained in the present study and previous studies indicate the importance of assessing the solubility, hence $H$ values, of organic substances in saline water (seawater) in order to accurately assess their partitioning and fate in seawater. The salting-out coefficients of organic compounds are known to be related to their partial molar volumes (Kutsuna et al., 2005). In the present study, molar volumes of OCPs were used since their partial molar volumes were not available. Salting-out constants $\left(k_{\mathrm{s}}\right)$ of OCPs increased with the increasing molar volume and the relationship was statistically significant $\left(r^{2}=0.36, p<0.01\right)$. However, molar volume could not account for all the variation in $k_{\mathrm{s}}$ values. Recently, a similar relationship was also observed between the $k_{\mathrm{s}}$ values of 2,2,2-trifluoroethyl formate, ethyl trifluoroacetate, and non-fluorinated analogous esters and their molar volumes (Kutsuna et al., 2005).

\section{References}

Altschuh, D.H.F., Brüggemann, R., Santl, H., Eichinger, G., Pringer, O.G., 1999. Henry's law constants for a diverse set of organic chemicals: experimental determination and comparison of estimation methods. Chemosphere 39, 1871-1887.

Bamford, H.A., Poster, D.L., Baker, J.E., 1999. Temperature dependence of Henry's law constants of thirteen polycyclic aromatic hydrocarbons between 4 degrees $\mathrm{C}$ and 31 degrees C. Environmental Toxicology and Chemistry 18, 1905-1912.

Bamford, H.A., Poster, D.L., Baker, J.E., 2000. Henry's law constants of polychlorinated biphenyl congeners and their variation with temperature. Journal of Chemical and Engineering Data 45, 1069-1074.

Cetin, B., Odabasi, M., 2005. Measurement of Henry's law constants of seven polybrominated diphenyl ether (PBDE) congeners as a function of temperature. Atmospheric Environment 39, 5273-5280. 
Chiou, C.T., Schmedding, D.W., Manes, M., 2005. Improved prediction of octanol-water partition coefficients from liquidsolute water solubilities and molar volumes. Environmental Science and Technology 39, 8840-8846.

Demou, E., Donaldson, D.J., 2002. Adsorption of atmospheric gases at the air-water interface. 4: the influence of salts. Journal of Physical Chemistry A 106, 982-987.

Gossett, J.M., 1987. Measurement of Henry's law constants for $\mathrm{C} 1$ and $\mathrm{C} 2$ chlorinated hydrocarbons. Environmental Science and Technology 21, 202-208.

Harrison, M.A.J., Cape, N.J., Mathew, R., Heal, M.R., 2002. Experimentally determined Henry's law coefficients of phenol, 2-methylphenol and 2-nitrophenol in the temperature range 281-302 K. Atmospheric Environment 36, 1843-1851.

Hinckley, D.A., Bidleman, T.F., Foreman, W.T., Tuschall, J.R., 1990. Determination of vapor pressures for nonpolar and semipolar organic compounds from gas chromatographic retention data. Journal of Chemical and Engineering Data 35, 232-237.

Jantunen, L.M.M., Bidleman, T.F., 2000. Temperature dependent Henry's law constant for technical toxaphene. Chemosphere-Global Change Science 2, 225-231.

Jantunen, L.M.M., Bidleman, T.F., 2006. Henry's law constants for hexachlorobenzene, $p, p^{\prime}$-DDE and components of technical chlordane and estimates of gas exchange for Lake Ontario. Chemosphere 62, 1689-1696.

Kucklick, J.R., Hinckley, D.A., Bidleman, T.F., 1991. Determination of Henry's law constants for hexachlorocyclohexanes in deionized water and artificial seawater as a function of temperature. Marine Chemistry 34, 197-209.

Kutsuna, S., Chen, L., Abe, T., Mizukado, J., Uchimaru, T., Tokuhashi, K., Sekiya, A., 2005. Henry's law constants of 2,2,2-trifluoroethyl formate, ethyl trifluoroacetate, and nonfluorinated analogous esters. Atmospheric Environment 39, 5884-5892.

Macdonald, R.W., Barrie, L.A., Bidleman, T.F., Diamond, M.L., Gregor, D.J., Semkin, R.J., Strachan, W.M.J., Li, Y.F., Wania, F., Alaee, M., Alexeeva, L.B., Backus, S.M., Bailey, R., Bewers, J.M., Gobeil, C., Halsall, C.J., Harner, T., Hoff, J.T., Jantunen, L.M.M., Lockhart, W.L., Mackay, D., Muir, D.C.G., Pudykiewicz, J., Reimer, K.J., Smith, J.N., Stern, G.A., Shroeder, W.H., Waemann, R., Yunker, M.B., 2000. Contaminants in the Canadian Arctic: 5 years of progress in understanding sources, occurrence and pathways. The Science of the Total Environment 254, 93-234.

Meylan, W.M., Howard, P.H., 1991. Bond contribution method for estimating Henry's law constants. Environmental Toxicology and Chemistry 10, 1283-1293.

Ni, N., Yalkowsky, H., 2003. Prediction of Setschenow constants. International Journal of Pharmaceutics 254, $167-172$

Odabasi, M., Cetin, B., Sofuoglu, A., 2006. Henry's law constant, octanol-air partition coefficient and supercooled liquid vapor pressure of carbazole as a function of temperature: application to gas/particle partitioning in the atmosphere. Chemosphere 62, 1087-1096.

Paasivirta, J., Sinkkonen, S., Mikkelson, P., Rantio, T., Wania, F., 1999. Estimation of vapor pressures, solubilities and
Henry's law constants of selected persistent organic pollutants as functions of temperature. Chemosphere 39, 811-832.

Palm, A., Cousins, I.T., Mackay, D., Tysklind, M., Metcalfe, C., Alae, M., 2002. Assessing the environmental fate of chemicals of emerging concern: a case study of the polybrominated diphenyl ethers. Environmental Pollution 117, 195-213.

Rice, C.P., Chernyak, S.M., McConnell, L.L., 1997. Henry's law constants for pesticides measured as a function of temperature and salinity. Journal of Agricultural Food Chemistry 45, 2291-2298.

Sahsuvar, L., Helm, P.A., Jantunen, L.M., Bidleman, T.F., 2003. Henry's law constants for $\alpha$-, $\beta$-, and $\gamma$-hexachlorocyclohexanes (HCHs) as a function of temperature and revised estimates of gas exchange in Arctic regions. Atmospheric Environment 37, 983-992.

Schwarzenbach, R.P., Gschwend, P.M., Imboden, D.M., 1993 Environmental Organic Chemistry. Wiley-Interscience, New York.

Schwarzenbach, R.P., Gschwend, P.M., Imboden, D.M., 2003. Environmental Organic Chemistry, Second ed. Wiley-Interscience, New York.

Shen, L., Wania, F., 2005. Compilation, evaluation, and selection of physical-chemical property data for organochlorine pesticides. Journal of Chemical and Engineering Data 50, 742-768.

Shoeib, M., Harner, T., 2002. Using measured octanol-air partition coefficients to explain environmental partitioning of organochlorine pesticides. Environmental Toxicology and Chemistry 21, 984-990.

Staudinger, J., Roberts, P.V., 2001. A critical compilation of Henry's law constant temperature dependence relations for organic compounds in dilute aqueous solution. Chemosphere 44, 561-576.

ten Hulscher, T.E.M., Van Der Velde, L.E., Bruggeman, W.A., 1992. Temperature dependence of Henry's law constants for selected chlorobenzenes, polychlorinated biphenyls and polycyclic aromatic hydrocarbons. Environmental Toxicology and Chemistry 11, 1595-1603.

TOXNET, 2005. Toxicology Data Network (United States National Library of Medicine), http://toxnet.nlm.nih.gov/.

Vallack, H.W., Bakker, D.J., Brandt, I., Broström-Lunden, E., Brouwer, A., Bull, K.R., Gough, C., Guardans, R., Holoubeck, I., Jansson, B., Koch, R., Kuylenstierna, J., Lecloux, A., Mackay, D., McCutcheon, P., Mocarelli, P., Taalman, R.D.F., 1998. Controlling persistent organic pollutants-what next? Environmental Toxicology and Pharmacology 6, $143-175$.

Wania, F., Dugani, C.B., 2003. Assessing the long range transport potential of polybrominated diphenyl ethers: a comparison of four multimedia models. Environmental Toxicology and Chemistry 22, 1252-1261.

Xiao, H., Li, N., Wania, F., 2004. Compilation, evaluation and selection of physical-chemical property data for $\alpha$-, $\beta$ - and $\gamma$ hexachlorocyclohexane. Journal of Chemical and Engineering Data 49, 173-185.

Xie, W.-H., Shiu, W.-Y., Mackay, D., 1997. A review of the effect of salts on the solubility of organic compounds in seawater. Marine Environmental Research 44, 429-444. 